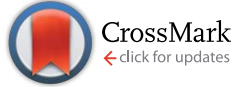

Cite this: Chem. Sci., 2016, 7, 5302

\title{
Combined aggregation induced emission (AIE), photochromism and photoresponsive wettability in simple dichloro-substituted triphenylethylene derivatives $\uparrow$
}

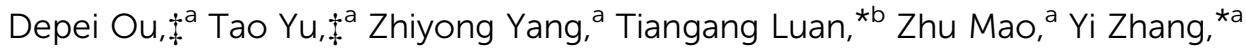 \\ Siwei Liu, ${ }^{a}$ Jiarui $\mathrm{Xu}^{a}{ }^{a}$ Zhenguo $\mathrm{Chi}^{\star a}$ and Martin R. Bryce ${ }^{\mathrm{c}}$
}

A dichloro-substituted triphenylethylene derivative $\left(\mathrm{TrPECl}_{2}\right)$ with aggregation-induced emission (AIE), photochromism and photoresponsive wettability has been synthesized. The new compound shows fastresponse photochromic behaviour with good ON/OFF repeatability by utilizing a proposed stilbene-type intramolecular photocyclization in the solid state. Compared with the more usual diphenylethylene derivatives, the photochromic properties of the triphenylethylene derivative are much more striking and easier to achieve. The triphenylethylene derivative also displays AIE properties leading to strong fluorescence in the solid state. Therefore, both the ultraviolet-visible absorption and fluorescence emission are drastically changed during the photochromic processes. Furthermore, the morphology of the $\mathrm{TrPECl}_{2}$ microcrystalline surface could be controlled by irradiation. The wettability of the surface could be drastically decreased with contact angles of a water droplet changing from $73^{\circ}$ to $118^{\circ}$. The triphenylethylene derivative with a simple molecular structure is, therefore, attractive for multifunctional materials.

Received 16th March 2016

Accepted 23rd April 2016

DOI: $10.1039 / \mathrm{c} 6 \mathrm{sc01205a}$

www.rsc.org/chemicalscience

\section{Introduction}

Photochromic materials are a type of photoresponsive compounds which undergo reversible chemical transformations between two (or more) well-defined states which have different optical properties. In recent years they have attracted much attention for their fundamental properties and for their emerging applications in security markings, optical shutters, photo-switchable molecular devices and optical memory storage systems. ${ }^{1,2}$ Accordingly, a wide range of photochromic systems have been developed, including stilbeneand azo-containing compounds, ${ }^{3}$ spirooxazine, ${ }^{4}$ spiropyran $^{5}$ and diarylethen $e^{6}$ (especially dithienylethene), and dihydroazulene derivatives. ${ }^{7}$

${ }^{a}$ PCFM Lab, GDHPPC Lab, Guangdong Engineering Technology Research Center for High-performance Organic and Polymer Photoelectric Functional Films, State Key Laboratory of OEMT, School of Chemistry and Chemical Engineering, Sun Yat-sen University, Guangzhou 510275, China. E-mail: ceszy@mail.sysu.edu.cn; chizhg@ mail.sysu.edu.cn

${ }^{b} M O E$ Key Laboratory of Aquatic Product Safety, School of Life Sciences, South China Sea Bio-Resource Exploitation and Utilization Collaborative Innovation Center, Sun Yat-sen University, Guangzhou 510275, China. E-mail: cesltg@mail.sysu.edu.cn 'Department of Chemistry, Durham University, Durham DH1 3LE, UK

$\dagger$ Electronic supplementary information (ESI) available: Synthetic procedures, experimental details and supplemental figures. See DOI: 10.1039/c6sc01205a

‡ Dr D. Ou and Dr T. Yu contributed equally to this work.
Photochromic materials are also investigated as topographical change materials. ${ }^{8}$ Furthermore, the wettability of the surfaces could be changed with morphology control by irradiation. ${ }^{8,9}$ In previous studies, topographical change properties of diarylethene derivatives have been systematically investigated by Uchida, ${ }^{10}$ Kobatake, ${ }^{11}$ and other groups. ${ }^{12}$ Spiropyran and azo-containing compounds have also been used as topographical change materials. ${ }^{13}$ Widespread applications are still restricted by the unstable surface properties, the demands of long irradiation time and complex synthetic procedures. Therefore, fast-response photochromic systems with simple molecular structures obtained from readily-available starting materials are in high demand.

In this regard, diphenylethylene derivatives have been investigated. However, their photochromic properties are difficult to observe as the key cyclization reaction occurs only for the cis-isomer and the ring-closed states are quite unstable. ${ }^{1}$ Triphenylethylene derivatives can overcome these problems and might, therefore, be ideal fast-response photochromic systems. In addition, introducing halogen atoms into triphenylethylene derivatives can be expected to thereby enhance the ring-closing photochromic process. ${ }^{6 a-e}$

Triphenylethylene derivatives are also well known as aggregation-induced emission (AIE) molecules. In contrast to the aggregation-caused quenching (ACQ) process, the emission intensities of AIE molecules are significantly increased by 
aggregation where the restriction of intramolecular rotation can efficiently avoid the usual emission quenching in the solid state. Since the pioneering work of Tang et al. in $2001,{ }^{14}$ several AIE systems have been developed including silole, ${ }^{15}$ tetraphenylethene, ${ }^{\mathbf{1 6}}$ and triphenylethylene derivatives ${ }^{\mathbf{1 7}}$ and others. ${ }^{\mathbf{1 8}}$ AIE has applications in OLED materials, piezochromic materials, chemosensors, photosensitizers and biolabels. ${ }^{\mathbf{1 4 - 1 8}}$ We are aware of only one report of molecules which show both photochromic and AIE properties. During the course of our present studies, Tang et al. described fast responsive, photoreversible and thermo-irreversible photochromic properties of three tetraarylethene-based polycyclic hydrocarbons which are AIE active. ${ }^{19}$

Triphenylethylene derivatives were first reported to be AIE active by Chi et al. ${ }^{17 a}$ and the piezochromic properties of these molecules have been widely investigated. ${ }^{17 d}$ We now report the first example of triphenylethylene derivatives which possess combined AIE, photochromic and photoresponsive wettability properties, namely $\mathrm{TrPECl}_{2}$ (Scheme $\left.\mathrm{S} 1 \dagger\right)$. As in Tang's recent report, ${ }^{19}$ photochromism arises due to the photocyclization of stilbene moieties in the chromophores. Compared with previous AIE photochromic system, the response times of the triphenylethylene derivatives are shortened from minutes to seconds. Therefore, these materials have advantages in the areas of optical shutters and photo-switchable molecular devices. $^{20}$ To the best of our knowledge, there has been no previous report of an AIE-photochromic-photoresponsive wettability system with such simple structures and short response times. The straightforward synthetic route to TrPE and $\mathrm{TrPECl}_{2}$ is shown in Scheme S1 in the ESI. $\dagger$

\section{Results and discussion}

Triphenylethylene (TrPE) is a typical AIE unit for the construction of AIE-active molecules ${ }^{\mathbf{1 7}}$ and compound $\mathrm{TrPECl}_{2}$ also shows AIE properties. AIE behavior in solution is commonly proven by the enhancement of emission, resulting from fluorescent nanoparticle formation by increasing the ratio of a poor solvent. ${ }^{14-18}$ The data for $\mathrm{TrPECl}_{2}$ in $\mathrm{THF} /$ water mixed solvent system at room temperature is shown in Fig. 1. In the pure THF solution (good solvent), the photoluminescence (PL) of the compound is not detectable. This can be attributed to the fact that intramolecular rotation, which serves as the relaxation channel for the excited state to decay, is active. However, when the water fraction reached $90 \%(\mathrm{v} / \mathrm{v})$ (water is a poor solvent for $\mathrm{TrPECl}_{2}$ ), the PL intensity was boosted by many fold with an emission peak at $\lambda_{\max } 425 \mathrm{~nm}$. This dramatic enhancement in luminescence indicates that the nanoparticles are formed in the proportion of $90: 10(\mathrm{v} / \mathrm{v})$ water/THF, and that intramolecular rotation is restricted due to aggregation of the molecules, as is typically observed in AIE-active molecules. The emission band mainly originates from the $\pi-\pi^{*}$ transition of the triphenylethylene moieties according to previous reports. ${ }^{17 \boldsymbol{a}} \mathrm{UV}$-vis spectra of $\mathrm{TrPECl}_{2}$ in $\mathrm{THF} /$ water mixed solutions containing $0 \%$ and $90 \%$ water fractions are shown in Fig. S2. $\dagger$ It is obvious that the baseline is enhanced when the water fraction reached $90 \%$, which indicates the formation of nanoparticles. ${ }^{21}$

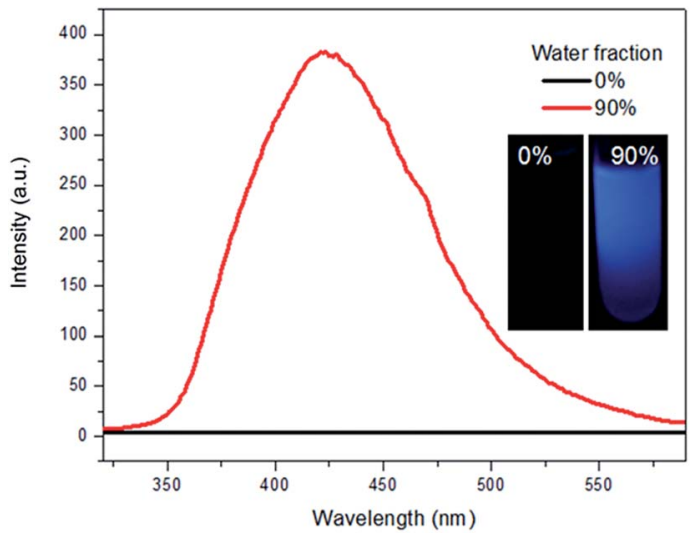

Fig. 1 Emission spectra of $\mathrm{TrPECl}_{2}$ in $\mathrm{THF} /$ water mixed solutions containing $0 \%$ and $90 \%$ water fractions; the inset shows the photographs of $\mathrm{TrPCl}_{2}$ in $\mathrm{THF} /$ water mixed solutions containing $0 \%$ and $90 \%$ water fractions.

For compound $\operatorname{TrPECl}_{2}$, blue emission is observed in the solid state upon excitation with UV light (365 nm), which is similar to that in AIE studies. Meanwhile, the color of the solid rapidly changes from white into bright red under UV irradiation as shown in Fig. 2(b) and the blue emission is quenched subsequently as shown in Fig. 2(d). The red solid reverts into a white solid after several seconds, and the photochromic bleaching process is described in Fig. 3. After turning to white, the emission can be observed under UV irradiation again. This cycle can be repeated many times without significant fatigue.
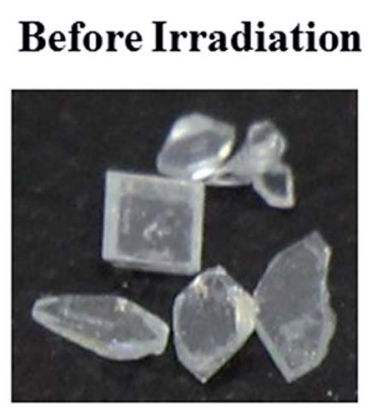

(a)

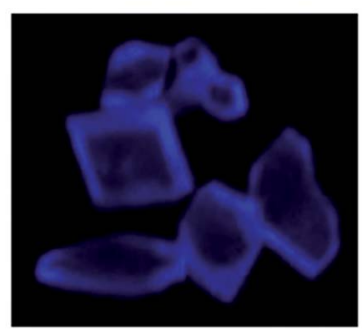

(c)

\section{After Irradiation}

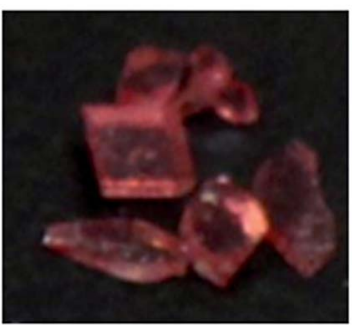

(b)

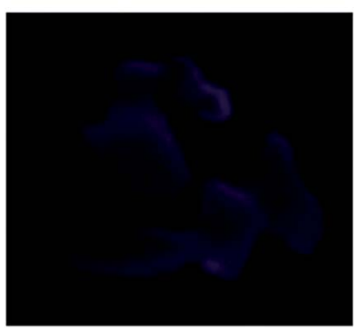

(d)
Fig. 2 Photographs of the crystals of $\mathrm{TrPECl}_{2}$ : (a) Before irradiation, the picture was taken under room lighting, (b) after irradiation, the picture was taken under room lighting, (c) before irradiation, the picture was taken under UV light, and (d) after irradiation, the picture was taken under UV light. 


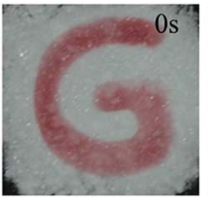

(a)

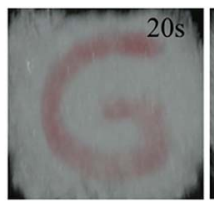

(b)

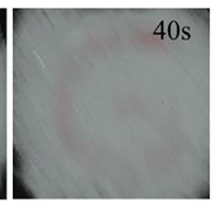

(c)

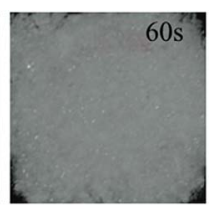

(d)
Fig. 3 Photochromic bleaching process of $\mathrm{TrPECl}_{2}$ at room temperature after irradiation with UV light stopped for: (a) $0 \mathrm{~s}$, (b) $20 \mathrm{~s}$, (c) $40 \mathrm{~s}$, and (d) $60 \mathrm{~s}$

The repeatability of the photochromic process will be discussed later. TrPE shows similar photochromic properties with shorter irradiation saturation times and photochromic bleaching times under the same conditions.

To further evaluate the photochromic properties of $\mathrm{TrPECl}_{2}$ and TrPE, time dependent UV-vis reflectance spectroscopy studies were carried out: the spectra of $\mathrm{TrPECl}_{2}$ under irradiation are shown in Fig. 4(a). In the UV-vis reflectance spectra, the absorption bands below $400 \mathrm{~nm}$ are assigned as $\pi-\pi^{*}$ transitions, in accordance with previous studies of triphenylethylene derivatives. ${ }^{17,22}$ Before irradiation, bleaching signals with $\lambda_{\max }$ of $429 \mathrm{~nm}$ were also detected in the UV-vis reflectance spectra, mainly due to the emission of $\mathrm{TrPECl}_{2}$. As shown in Fig. 4(a), the low-energy absorption bands at around $514 \mathrm{~nm}$ increase with the irradiation time, suggesting increased conjugation in the molecule. Meanwhile, the bleaching signals at $429 \mathrm{~nm}$ gradually

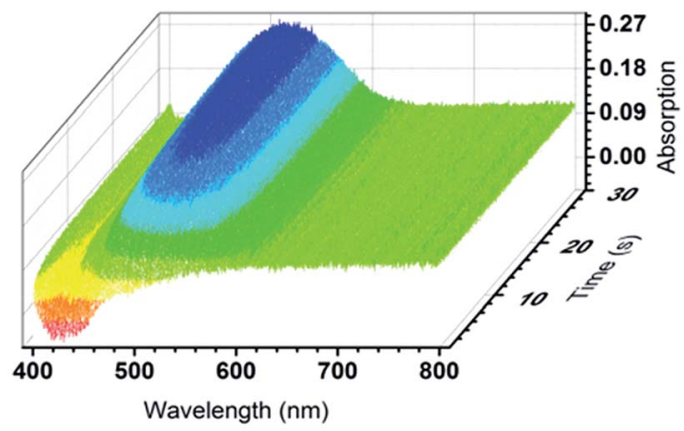

(a)

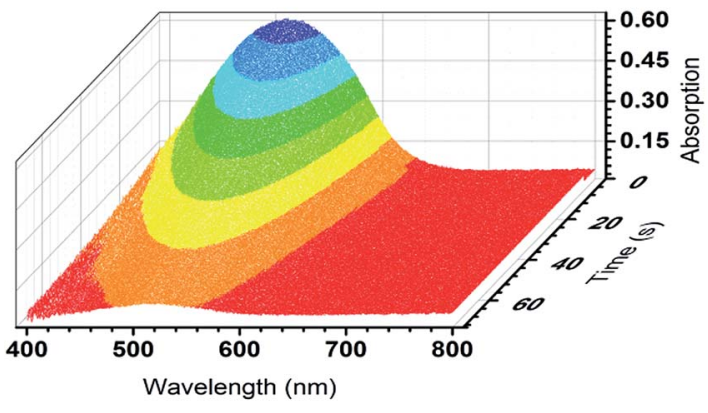

(b)

Fig. 4 (a) Time dependent UV-vis reflectance spectra of $\mathrm{TrPCl}_{2}$ during the irradiation process. (b) Time dependent UV-vis reflectance spectra of $\mathrm{TrPECl}_{2}$ during the photochromic bleaching process. decrease to zero with the quenching of emission, which is in accordance with the phenomena described in Fig. 2. After $30 \mathrm{~s}$, the absorption bands at $514 \mathrm{~nm}$ reach their maximum intensity and no increase is observed with further irradiation under a deuterium light source (irradiation saturation time). Fig. 4(b) shows the time dependent UV-vis reflectance spectra for the photochromic bleaching process of over-irradiated $\mathrm{TrPECl}_{2}$. The absorption bands at $514 \mathrm{~nm}$ decreased as soon as the irradiation stopped and disappeared after $60 \mathrm{~s}$ (photochromic bleaching time). It could be detected that the absorption spectra in Fig. 4(b) are broader than in Fig. 4(a). This is mainly due to the bleaching signals (emission bands of $\mathrm{TrPECl}_{2}$ ) under UV irradiation during the photochromic process. The compound TrPE shows shorter irradiation saturation time $(<1$ s) and photochromic bleaching time within $1 \mathrm{~s}$ at ambient room temperature and lighting. The much shorter irradiation and photochromic bleaching processes are mainly due to the instability of the ring-closed structures of TrPE, which will be discussed later. It should be noted that the photochromic processes of TrPE and $\mathrm{TrPECl}_{2}$ are generally much faster than the previously reported AIE-photochromic systems ( $c a .60 \mathrm{~s}) .{ }^{19}$ The increase and decrease of the reflectance of $\mathrm{TrPECl}_{2}$ and TrPE at $515 \mathrm{~nm}$ as a function of time are shown in Fig. $4(\mathrm{a}$ and $\mathrm{b}$ ) and Fig. $\mathrm{S} 5, \uparrow$ respectively. The repeated photochromic switching processes of $\mathrm{TrPECl}_{2}$ are shown in Fig. $\mathrm{S} 6 \dagger$ for 20 cycles without fatigue. Good repeatability of these photochromic materials indicates their potential applications as rewritable materials. It is obvious from these data that triphenylethylene derivatives show both fast-response properties and high stabilities in the photochromic processes.

In the triphenylethylene derivatives, the distance between the phenyl rings and the ethene-1,1-diyldibenzene moieties are short enough for ring-closure reactions. ${ }^{17,22}$ The photochromic response after irradiation is assigned to a stilbene-type 6- $\pi$ electron ring-closure as depicted in Fig. 5. The ring-closure of similar structures has been reported in previous studies. ${ }^{17,22}$ In contrast to the previous report on AIE-photochromic materials, ${ }^{19}$ the structure of $\operatorname{TrPECl}_{2}(\mathrm{~B})$ is unstable and quickly reverted to structure $\operatorname{TrPECl}_{2}(\mathrm{~A})$ even in the dark at room temperature. The instability of the $\operatorname{TrPECl}_{2}(\mathrm{~B})$ structure indicates a lower energy barrier during the photochromic process, which is in accordance with the less extended $\pi$ structure compared with the previously reported system. ${ }^{23}$ After irradiation for many cycles in air, the white solid $\operatorname{TrPECl}_{2}(\mathrm{~A})$ became a pale yellow color. This solid is weakly emissive in solution which is different from pure compounds $\operatorname{TrPECl}_{2}(\mathrm{~A})$ and $\mathrm{TrPECl}_{2}(\mathrm{~B})$, which are non-emissive in solution. According to a previous study, the yellow colour after irradiation is mainly

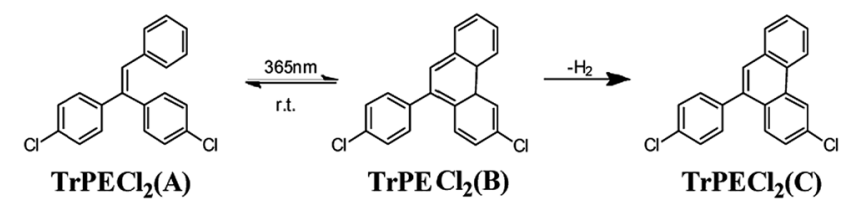

Fig. 5 Proposed mechanism of the photochromism of $\mathrm{TrPECl}_{2}$. 
due to the dehydrogenation process of compound $\operatorname{TrPECl}_{2}(\mathrm{~B})$ in the presence of oxygen to afford $\operatorname{TrPECl}_{2}(\mathrm{C})$ (Fig. 5). ${ }^{19,23}$ However, the photochromic processes of these compounds were not observed in solution states. This is mainly attributed to the twisted structures of these AIE molecules in solution states that resist the ring-closure reaction. Similar results were also reported in AIE photochromic materials in previous studies. ${ }^{19}$

In an attempt to provide evidence for structure $\operatorname{TrPECl}_{2}(\mathrm{C})$, a photo-oxidation reaction was performed: compound $\mathrm{TrPECl}_{2}$ was irradiated for $48 \mathrm{~h}$ in the solid state in the presence of air. The pale yellow solid was formed, which was proposed to be the dehydrogenated product $\operatorname{TrPECl}_{2}(\mathrm{C})$. The ${ }^{1} \mathrm{H}$ NMR spectrum of this solid showed additional peaks in the aromatic region compared to compound $\operatorname{TrPECl}_{2}(\mathrm{~A})$, consistent with the formation of the dehydrogenated phenanthrene derivative $\mathrm{TrPECl}_{2}(\mathrm{C})$ as shown in Fig. S7 and S8 in the ESI. $\uparrow$ To further confirm the structure of $\operatorname{TrPECl}_{2}(\mathrm{C})$, a small amount of $\mathrm{TrPECl}_{2}(\mathrm{C})$ was purified from the irradiated product using silica gel column chromatography with hexane as eluent. The high resolution EI mass spectrum of $\operatorname{TrPECl}_{2}(\mathrm{C})$ is shown in Fig. S9† and offers validation.

The $\mathrm{TrPECl}_{2}$ microcrystalline surfaces were initially prepared by spin-coating a $\mathrm{TrPECl}_{2}$ dichloromethane solution $\left(5 \mathrm{mg} \mathrm{mL}{ }^{-1}\right.$ ) onto two identical pieces of $\mathrm{SiO}_{2}$ substrate. After the solvent was evaporated under vacuum at room temperature, one $\mathrm{TrPECl}_{2}$ microcrystalline surface (surface A) was formed after storage in the dark for 3 days at ambient temperature (around $303 \mathrm{~K}$ ). The other microcrystalline surface (surface B) was formed by irradiation under UV light $(365 \mathrm{~nm}$ ) for 3 minutes and followed by storage in the dark for 3 days at room temperature. Scanning electron microscopy (SEM) and contact angle analysis studies were carried out to establish the morphology of $\mathrm{TrPECl}_{2}$ microcrystalline surfaces without or with irradiation. The SEM images without or with irradiation are displayed in Fig. 6(a and b) and (d and e), respectively. On surface $A$, without the 3 minutes irradiation, microcrystals of $\mathrm{TrPECl}_{2}$ with rod-shape-crystals gradually

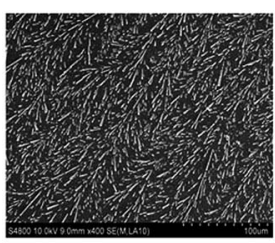

(a)

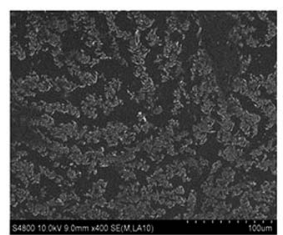

(d)

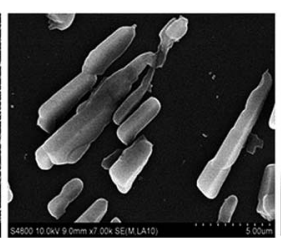

(b)

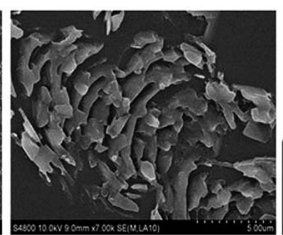

(e)

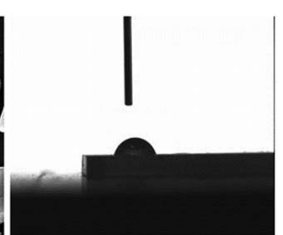

(c)

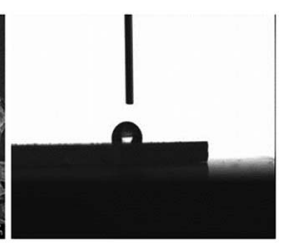

(f)
Fig. 6 Surface morphology control of $\mathrm{TrPECl}_{2}$ by irradiation: ( $a$ and $b$ ) SEM image of surface A (without irradiation); (c) contact angle of the water droplet on surface $A$; ( $d$ and e) SEM image of surface $B$ (with irradiation); (f) contact angle of the water droplet on surface $B$. grew in the dark. A branched pattern was formed on the surface by the rod-shape-crystals as shown in Fig. 6(a). The contact angle of a water droplet on surface A is $73^{\circ}$ (Fig. 6(c)). However, the microcrystals of $\mathrm{TrPECl}_{2}$ on surface $\mathrm{B}$ grew into a different pattern of scale-shaped crystals (Fig. 6(d and e)) and the contact angle of a water droplet on surface $B$ increases from $73^{\circ}$ to $118^{\circ}$ (Fig. 6(f)). These results demonstrate that irradiation strongly affects the patterns of $\mathrm{TrPECl}_{2}$ microcrystals and further controls the wettability of surfaces. The topographical change of $\operatorname{TrPECl}_{2}$ microcrystals on the surface is mainly attributed to the formation of closed-ring isomer $\mathrm{TrPECl}_{2}$ (B) as nuclei at the beginning of crystal growth; a similar mechanism of the topographical change has been reported previously. ${ }^{10 d, 12}$ The $\operatorname{TrPECl}_{2}(\mathrm{~B})$ could be changed back to $\mathrm{TrPECl}_{2}$ (A) quickly in the crystal-growth process in the dark as mentioned above. It should be noted that these two surfaces with different patterns are formed with the same isomer $\left[\operatorname{TrPECl}_{2}(\mathrm{~A})\right]$ of the photochromic material that is very different from the topographical change and wettabilitycontrollable systems based on diarylethene derivatives. ${ }^{\mathbf{8 - 1 2}}$ These new topographically-changeable and wettabilitycontrollable surfaces are much more stable in the light because the different microcrystalline patterns are all formed by the stable isomer of the photochromic process. In addition, the photoresponsive patterning process requires much shorter irradiation time compared with the same process for diarylethene derivatives (usually several hours). ${ }^{8-12}$ These advantages could promote these topographically-changeable and wettability-controllable materials based on triphenylethylene for industrial applications.

\section{Conclusions}

In summary, a structurally-simple triphenylethylene derivative $\mathrm{TrPECl}_{2}$ has been successfully designed and synthesized and it provides a rare example of combined AIE, fast-responsive photochromism, and topographically-changeable and wettability-controllable properties in a single compound. To study the photochromic properties of these materials in the solid state, UV-vis reflectance spectroscopy studies have been performed. SEM and contact angle analysis have been used to investigate the morphology and wettability control of the $\mathrm{TrPECl}_{2}$ microcrystalline surfaces by irradiation. These new compounds enlarge our understanding of the photophysical and photochemical properties of triphenylethylene derivatives and present a new strategy to design multifunctional materials with simple structures.

\section{Acknowledgements}

The authors gratefully acknowledge the financial support from the NSF of China (51473185), 863 Program (SS2015AA031701), the Fundamental Research Funds for the Central Universities, Guangdong Science and Technology Plan (2015B090913003 and 2015B090915003) and CSC project (201506385012) and EPSRC (for the work in Durham). 


\section{Notes and references}

1 (a) R. M. Kellogg, M. B. Greon and H. Wynberg, J. Org. Chem., 1967, 32, 3093; (b) M. Irie, Chem. Rev., 2000, 100, 1685; (c) H. Tian and S. Yang, Chem. Soc. Rev., 2004, 33, 85; (d) F. M. Raymo and M. Tomasulo, Chem. Soc. Rev., 2005, 34, 327.

2 (a) G. M. Tsivgoulis and J.-M. Lehn, Angew. Chem., Int. Ed., 1995, 34, 1119; (b) S. Higgins, Chem. Br., 2003, 39, 26.

3 (a) H. Dürr, Angew. Chem., Int. Ed., 1989, 28, 413; (b) H. Dürr and T. H. Bouas-Laurent, Photochromism: Molecules and Systems, Elsevier, Amsterdam, 1990.

4 (a) R. J. Hovey, C. H. Fuchsman, N. Y. C. Chu and P. G. Piusz, photochromic compound, US Pat., 4215010, 1980; (b) A. K. Chibisov and H. Gçrner, J. Phys. Chem. A, 1999, 103, 5211; (c) V. W. W. Yam, C. C. Ko, L. Wu, K. M. C. Wong and K. K. Cheung, Organometallics, 2000, 19, 1820; (d) R. T. F. Jukes, B. Bozic, F. Hartl, P. Belser and L. De Cola, Inorg. Chem., 2006, 45, 8326.

5 (a) N. Tamai and H. Miyasaka, Chem. Rev., 2000, 100, 1875; (b) J. B. Flannery Jr, J. Am. Chem. Soc., 1968, 90, 5660; (c) D. Levy and D. Avnir, J. Phys. Chem., 1988, 92, 4734; (d) J. L. Bahr, G. Kodis, L. Garza, S. Lin, A. L. Moore, T. A. Moore and D. Gust, J. Am. Chem. Soc., 2001, 123, 7124; (e) H. R. Allcock and C. Kim, Macromolecules, 1991, 24, 2846.

6 (a) M. Irie and M. Mohri, J. Org. Chem., 1988, 53, 803; (b) A. Fernández-Acebes and J. M. Lehn, Adv. Mater., 1998, 10, 1519; (c) T. Kawai, T. Iseda and M. Irie, Chem. Commun., 2004, 72; (d) J. Zhang, W. Tan, X. Meng and H. Tian, J. Mater. Chem., 2009, 19, 5726; (e) P. H. M. Lee, C. C. Ko, N. Zhu and V. W. W. Yam, J. Am. Chem. Soc., 2007, 129, 6058; (f) T. Nakashima, M. Goto, S. Kawai and T. Kawai, J. Am. Chem. Soc., 2008, 130, 14570; ( $g$ ) V. Lemieux, M. D. Spantulescu, K. K. Baldridge and N. R. Branda, Angew. Chem., Int. Ed., 2008, 120, 5112.

7 (a) S. L. Broman and M. B. Nielsen, Phys. Chem. Chem. Phys., 2014, 16, 21172; (b) S. L. Broman, O. Kushnir, M. Rosenberg, A. Kadziola, J. Daub and M. B. Nielsen, Eur. J. Org. Chem., 2015, 19, 4119.

8 S. Nakamura, S. Yokojima, K. Uchida and T. Tsujioka, J. Photochem. Photobiol., C, 2011, 12, 138.

9 D. Kitagawa and S. Kobatake, Chem. Sci., 2012, 3, 1445.

10 (a) K. Uchida, N. Nishikawa, N. Izumi, S. Yamazoe, H. Mayama, Y. Kojima, S. Yokojima, S. Nakamura, K. Tsujii and M. Irie, Angew. Chem., Int. Ed., 2010, 49, 5942; (b) A. Uyama, S. Yamazoe, S. Shigematsu, M. Morimoto, S. Yokojima, H. Mayama, Y. Kojima, S. Nakamura and K. Uchida, Langmuir, 2011, 27, 6395; (c) N. Nishikawa, H. Kiyohara, S. Sakiyama, S. Yamazoe, H. Mayama, T. Tsujioka, Y. Kojima, S. Yokojima, S. Nakamura and K. Uchida, Langmuir, 2012, 28, 17817; (d) N. Nishikawa, S. Sakiyama, S. Yamazoe, Y. Kojima, E. Nishihara, T. Tsujioka, H. Mayama, S. Yokojima, S. Nakamura and K. Uchida, Langmuir, 2013, 29, 8164.
11 (a) D. Kitagawa, I. Yamashita and S. Kobatake, Chem. Commun., 2010, 46, 3723; (b) S. Kobatake, H. Hasegawa and K. Miyamura, Cryst. Growth Des., 2011, 11, 1223.

12 R. Oropesa-Nuñez, D. Fragouli and A. Athanassiou, Langmuir, 2014, 30, 13058.

13 (a) D. Fragouli and A. Athanassiou, Adv. Funct. Mater., 2008, 18, 1617; (b) A. U. Zillohu and M. Elbahri, Sci. Rep., 2014, 4, 7407; (c) S. Pan, R. Guo and W. Xu, Soft Matter, 2014, 10, 9187.

14 J. Luo, Z. Xie, J. W. Y. Lam, L. Cheng, C. Qiu, H. S. Kwok, X. Zhan, D. Liu, D. Zhu and B. Z. Tang, Chem. Commun., 2001, 1740.

15 (a) G. Yu, S. Yin, Y. Liu, J. Chen, X. Xu, X. Sun, D. Ma, X. Zhan, Q. Peng, Z. Shuai, B. Z. Tang, D. Zhu, W. Fang and Y. Luo, J. Am. Chem. Soc., 2005, 127, 6335; (b) Y. Hong, J. W. Y. Lam and B. Z. Tang, Chem. Commun., 2009, 4332.

16 (a) Y. Dong, J. W. Y. Lam, A. Qin, J. Liu, Z. Li, B. Z. Tang, J. Sun and H. S. Kwok, Appl. Phys. Lett., 2007, 91, 011111; (b) H. Li, X. Zhang, Z. Chi, B. Xu, W. Zhou, S. Liu, Y. Zhang and J. Xu, Org. Lett., 2011, 13, 556; (c) C. Y. K. Chan, Z. Zhao, J. W. Y. Lam, J. Liu, S. Chen, P. Lu, M. Faisal, X. Chen, H. H. Y. Sung, H. S. Kwok, Y. Ma, I. D. Williams, K. S. Wong and B. Z. Tang, Adv. Funct. Mater., 2012, 22, 378; (d) Z. Zhao, J. W. Y. Lam and B. Z. Tang, J. Mater. Chem., 2012, 22, 23726.

17 (a) Z. Yang, Z. Chi, T. Yu, X. Zhang, M. Chen, B. Xu, S. Liu, Y. Zhang and J. Xu, J. Mater. Chem., 2009, 19, 5541; (b) W. Qin, Z. Yang, Y. Jiang, J. W. Y. Lam, G. Liang, H. S. Kwok and B. Z. Tang, Chem. Mater., 2015, 27, 3892; (c) Z. Chi, X. Zhang, B. Xu, X. Zhou, C. Ma, Y. Zhang, S. Liu and J. Xu, Chem. Soc. Rev., 2012, 41, 3878; (d) B. Xu, J. He, Y. Mu, Q. Zhu, S. Wu, Y. Wang, Y. Zhang, C. Jin, C. Lo, Z. Chi, A. Lien, S. Liu and J. Xu, Chem. Sci., 2015, 6, 3236; (e) B. Xu, Y. Mu, Z. Mao, Z. Xie, H. Wu, Y. Zhang, C. Jin, Z. Chi, S. Liu, J. Xu, Y. Wu, P. Lu, A. Lien and M. Bryce, Chem. Sci., 2016, 7, 2201.

18 (a) Y. S. Zheng and Y. J. Hu, J. Org. Chem., 2009, 74, 5660; (b) H. C. Su, O. Fadhel, C. J. Yang, T. Y. Cho, C. Fave, M. Hissler, C. C. Wu and R. Reau, J. Am. Chem. Soc., 2006, 128, 983; (c) K. Kokado and Y. Chujo, Macromolecules, 2009, 42, 1418.

19 Z. He, L. Shan, J. Mei, H. Wang, J. W. Y. Lam, H. H. Y. Sung, I. D. Williams, X. Gu, Q. Miao and B. Z. Tang, Chem. Sci., $2015,6,3538$.

20 G. Wirnsberger, B. J. Scott, B. F. Chmelka and G. D. Stucky, Adv. Mater., 2000, 12, 1450.

21 B. Z. Tang, Y. Geng, J. W. Y. Lam, B. Li, X. Jing, X. Wang, F. Wang, A. B. Pakhomov and X. Zhang, Chem. Mater., 1999, 11, 1581.

22 X. Zhou, H. Li, Z. Chi, B. Xu, X. Zhang, Y. Zhang, S. Liu and J. Xu, J. Fluoresc., 2012, 22, 565.

23 (a) T. S. Navale, K. Thakur and R. Rathore, Org. Lett., 2011, 13, 1634; (b) M. C. Smith, J. A. Snyder, B. C. Streifel and A. E. Bragg, J. Phys. Chem. Lett., 2013, 4, 189; (c) U. Mazzucato and A. Spalletti, J. Phys. Chem. A, 2009, 113, 14521; (d) J. Ma, T. Lin, X. Pan and W. Wang, Chem. Mater., 2014, 26, 4221; (e) J. A. Snyder and A. E. Bragg, J. Phys. Chem. A, 2015, 119, 3972. 